\title{
La estética del trauma y el discurso de la memoria: personajes infantiles ante el terror estatal en Infancia clandestina (Ávila, Argentina, 2011)
}

\section{Tal, Tzvi}

Resumen: Analizando las funciones alegóricas e ideológicas de narrativas cinematográficas de iniciación centradas en personajes infantiles que recuerdan las dictaduras militares, la presencia del concepto de Genocidio en el discurso sobre el terror estatal ejercido por la última dictadura cívico militar y los usos de la animación como artefacto estético que representa momentos traumáticos considerados irrepresentables mediante la estética realista, el articulo sostiene que Infancia clandestina prosigue una corriente particular de cine de Hijos de desaparecidos, ofreciendo una visión del pasado que idealiza a los combatientes Montoneros pero cuestiona el precio personal que pagan los huérfanos.

Esta variante, alternativa a la memoria

Cuadernos del Centro de Estudios de Diseño y Comunicación Nº 68

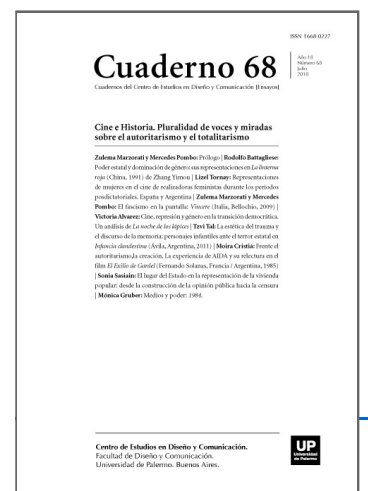

ISSN: 1668-0227

Cine e Historia.

Pluralidad de voces y

miradas sobre el

autoritarismo y el

totalitarismo

Año XVIII, Julio 2018, Buenos Aires, Argentina | 148 páginas

descargar PDF ver índice de la publicación

Ver todos los libros de la publicación

compartir en Facebook

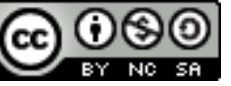

Esta obra está bajo una Licencia Creative Commons Atribución-NoComercialCompartirlgual 4.0 Internacional cinematográfica de la generación vinculada a la experiencia de la guerrilla Montonera, no se contrapone al discurso hegemónico durante los gobiernos de Nestor Kirchner y Cristina Fernández de Kirchner, sino se deslinda como un memoria particular que se ve parte del discurso kirchnerista.

Palabras clave: Alegoría - Infancia - Discurso - Holocausto - Genocidio - Memoria.

$\left(^{*}\right)$ Phd. Profesor con nominación permanente. Escuela para las Artes del Sonido y la Pantalla, Colegio Académico Sapir, Israel. Investiga representaciones de la Historia y la reconstrucción de los Héroes nacionales en cine, y la imagen del judío en el cine latinoamericano contemporáneo.

Memorias de película 
Las representaciones de la infancia y la adolescencia en los cines latinoamericanos contemporáneos permiten interpretar los significados alegóricos relacionados a la memoria del pasado y los conflictos presentes en películas de diversas procedencias que evocan el pasado de las dictaduras de las décadas de los setentaochenta del siglo XX desde el punto de vista de personajes de niños o adolescentes tempranos, tales como Kamchatka (Piñeyro, Argentina, 2002), Machuca (Wood, Chile, 2004) o El año que mis padres salieron de vacaciones (Hamburguer, Brasil, 2006). Los protagonistas infantiles en las películas que rememoran los sucesos son el centro del impacto afectivo e intelectual que producen en el espectador y pueden ser interpretadas como alegorías de la nación. Por otro lado, la asidua representación de la dictadura cívico-militar 1976-1983 en el cine argentino testimonia el trauma que dicho período ha dejado en la cultura nacional, de modo que las narrativas cinematográficas de hijos de desaparecidos durante la dictadura construyen memorias ejemplares, donde la experiencia personal es transvasada al espacio público, pudiendo expresar un tono irritado e irritante respecto a la memoria colectiva que instituyen discursos hegemónicos; construyen un aspecto particular de la posmemoria que el cine contribuye a establecer en las generaciones posteriores. (Tal, 2005 y 2015; Tuñon y Tal, 2007; Dufays, 2014, Xavier 1999, Aón, 2009, Berger, 2008)

Con la transición a la democracia en 1983, el discurso social adoptaba el concepto de Genocidio, que designaba el extermino masivo de judíos cometido por la Alemania Nazi durante la Segunda Guerra Mundial para caracterizar los delitos contra los Derechos Humanos realizados por la última dictadura en Argentina (Feierstein, 2011). La memoria del Holocausto Judío, construida tanto por instituciones de la sociedad civil y estatales como por una disciplina académica con sus propias características, contribuye a la conformación de percepciones sobre acciones violentas y sus víctimas en el mundo contemporáneo a través del prisma del Genocidio (Huyssen, 2000). De este modo, algunas referencias a la representación cinematográfica del Holocausto son relevantes para interpretar las imágenes de la dictadura en películas argentinas. Un ejemplo fundacional es la secuencia inicial de La Historia Oficial (Puenzó, 1984), donde la puesta en pantalla del acto de apertura del último año lectivo bajo el gobierno de facto en un colegio secundario de la ciudad de Buenos Aires, incorpora la iconografía del Holocausto. El plano picado de estudiantes y profesores entonando el Himno Nacional transmitido por un parlante de mal sonido en filas formadas con paraguas en mano bajo la lluvia, se asemeja a la formación de prisioneros en narrativas cinematográficas que transcurren en campos de concentración, mientras que detrás pasa un tren suburbano, que pese a las diferencias obvias con los trenes usados por los nazis, evoca los transportes de judíos al exterminio. Sin embargo, dicha imagen es ambivalente, pues también recuerda la iconografía de los habitantes de Buenos Aires reunidos bajo la lluvia frente al Cabildo el 25 de Mayo de 1810, reclamando saber de que se trata. La secuencia expresa el discurso que señala al pueblo argentino como víctima de genocidio cometido por la dictadura. Pese a la diferencia entre la clasificación étnica de los judíos en Europa y la identificación política-ideológica de los opositores en Argentina de los setenta, los militares, como los nazis, extirpaban elementos que consideraban peligrosos para la sociedad. El militante era un factor patológico subversivo debía ser exterminado aunque hubiera dejado la práctica opositora; la categorización de la víctima era irreversible en ambos casos. (Korstanje, 2014)

Adoptando la aproximación que permite referirse a las películas como testimonios esté- ticos de los discursos sociales en el contexto social y cultural en que son producidas, me refiero a Infancia Clandestina como expresión de una de las opciones de memoria de la dictadura en la era de los gobiernos de Néstor y Cristina Kirchner, que impulsaron nuevamente la búsqueda y juicio de los culpables, haciendo de dicha política y de la memoria de los perseguidos parte de los ejes centrales de su discurso (Ferro, 1988; Sorlin, 1980, Rosenstone, 
1995; Marzorati y Tal, 2011, Montero, 2009). La memoria social es una memoria cultural, construida y definida por la popularización de la Historia difundida, entre otros vehículos, por las narrativas cinematográficas. Si bien el cine destinado a los circuitos de distribución comercial suele difundir versiones del pasado coherentes con la hegemonía ideológica contemporánea a la producción, el análisis textual, contextual e intertextual del filme puede distinguir variantes y giros discursivos, así como el surgimiento de discursos alternativos o contrahegemónicos. El cine puede ser concebido como un campo de batalla simbólica entre narrativas del pasado difundidas por discursos que asientan en su versión del pasado la legitimación del proyecto que aspiran a concretar en el presente y el futuro. (Baer, 2006; Tal, 2009)

Gran parte de los estudios referentes a las consecuencias de la violencia, y en particular de la violencia ejercida por el Estado, adopta la concepción del trauma basada en Freud y en los estudios del Holocausto judío. El trauma colectivo que afecta a la cultura que ha sufrido del terror estatal no puede ser explicado sólo por la experiencia personal, sino como un proceso prostético donde quienes no han experimentado los sucesos adquieren el trauma mediante aparatos culturales de representación, entre los que el cine se distingue por su aptitud a dicho trabajo; son las imágenes del Holocausto las que se imponen a las memorias, así como imágenes cinematográficas de acción, explosiones, tiroteos y muertes suministran a las memorias lo que no se ha experimentado en persona (LaCapra, 2005 ;Traverso and Broderick, 2010; Montealegre Iturra, 2012). Las memorias de las dictaduras en las películas con narrativas de iniciación infantil o adolescente manifiestan en su textura cinematográfica el intento de expresar el momento traumático relacionado a circunstancias históricas percibidas como practica genocida estatal. Por otro lado, las películas, producidas en el contexto neoliberal, son distribuidas y consumidas en el mercado de la memoria, de modo que el cierre de los conflictos al final de las películas minimiza las diferencias o conflictos de clase, para resaltar en su lugar los modos privados de amor, venganza o memoria (Tandezciarz, 2012). La aproximación que este artículo practica, se refiere a las convenciones genéricas de las narrativas de infancia en películas que enfocan la memoria de la dictadura como artefactos textuales que alegorizan los procesos de toma de conciencia y pérdida de la inocencia por los diversos sectores de la sociedad. Estos constituyen el mercado de consumo de los productos culturales, donde la capacidad de las películas de concientizar al espectador y estimular al cambio social es limitada. El aporte de las películas son las imágenes en las que la sociedad se puede ver reflejada, identificada, enfrentada y conmovida por "aquello de lo que no se habla". El discurso social acerca de las películas es el que podría movilizar procesos de cambio de conciencia que impulsaría el accionar político de los sujetos sociales.

\section{El pasado infantil y lo político}

Infancia Clandestina relata algunos meses de 1979 en la vida de un pre-adolescente hijo de combatientes montoneros en la clandestinidad. Durante ese tiempo experimentará el primer amor, aprenderá el precio de la clandestinidad y sufrirá la perdida de seres queridos. Películas de iniciación suelen incluir aspectos autobiográficos de los directores, aspecto ampliamente comentado en el caso de este film y convenientemente aclarado por el director. En mi aproximación, es un detalle más entre los datos contextuales, el análisis debe referirse también a los modos de representación, a las convenciones cinematográficas, a la intertextualidad, con el objeto de esclarecer el discurso que la película difunde. (Feinman, 2012)

Las versiones cinematográficas del pasado no se evalúan por la fidelidad a la historiografía o la distorsión de los hechos sino que deben ser encaradas como vehículos de los discursos sociales, responsables por las diferencias entre las versiones de pasado. La lectura histórica del filme es enriquecida por la lectura alegórica 
que interpreta el texto cinematográfico como una narrativa que se refiere a los procesos sociales fuera del texto, contemporáneos a la producción del film. La intencionalidad alegórica de los cineastas no es la relevante a nuestra lectura. En su lugar, son las características del texto -como fragmentación de la continuidad, alternación de estéticas, modos de representación, etc.- las que estimulan a producir la lectura alegórica con la que nos construimos como sujeto, estableciendo nuestra postura respecto a las representaciones y los discursos que las producen (Xavier, 1999). Por otro lado, el modo de movilización social practicado por el discurso K presenta los conflictos desde puntos de vista particulares, enfocados en casos de personas o sectoriales, donde la implementación de medidas apropiadas tendrá repercusión en sectores mas amplios, de modo que la vinculación de lo político con los artístico se torna patente. (Murillo Saban, 2013)

Las narrativas donde el personaje infantil es introducido a las relaciones sociales, suelen desarrollarse en estrecho contacto con el marco familiar, que es uno de los aparatos primordiales de adaptación del individuo a la comunidad imaginada, de modo que también las representaciones de la familia pueden ser interpretadas como alegorías que testimonian los conflictos y las limitaciones característicos de la sociedad. La empatía que generan los personajes infantiles en el espectador es parte del trabajo de encubrimiento de la ideología y el discurso imbuidos en el texto fílmico. El descubrimiento por el protagonista de la sexualidad entre los padres u otros personajes, puede ser interpretado como una metáfora que simboliza el aprendizaje de la complejidad de la vida adulta y de los procesos sociales. Por ejemplo, el protagonista de Kamtchatka solo percibe voces y gemidos provenientes de la habitación de sus padres, así como la película no explicita las posturas políticas o la militancia de los mismos, infantilizando la memoria y despolitizando la historia. Nunca durante el film sabrá el protagonista cual era la militancia orgánica o la ideología expresa de los padres perseguidos. En cambio, el protagonista de Machuca percibe la decadencia del vínculo conyugal entre sus padres burgueses y entre los de su amigo pobre, así como la película expone en modo simétrico los conflictos ideológicos y callejeros entre izquierda y derecha previos al golpe contra el gobierno de Salvador Allende. Se politiza la memoria presentando en forma esquemática los conflictos discursivos, pero se infantiliza la historia representándolos en una asimetría falta de asidero en el pasado. (Tal, 2005)

Infancia clandestina se diferencia de Kamtchatka explicitando la militancia montonera de los padres, pero coincide con ella en la casi total ignorancia del protagonista acerca de la misma, así como sólo percibe en suspiros acallados la vida íntima de los padres. La situación del protagonista es peor aún, pues es la familia misma la que provoca la inseguridad del niño al impedirle la amistad y el amor incipiente y al imponerle una vida de ficción de la cual solo la intervención asesina de los parapoliciales lo devolverá a la realidad de su identidad y a la orfandad (Varela, 2016). La película se distingue también de Machuca evitando precisar el proyecto ideológico Montonero. En cambio difunde una versión del pasado que atribuye a los grupos parapoliciales desatar la violencia luego de la muerte de Perón en 1974, absteniéndose de recordar la violencia previa de ambos lados, por ejemplo el asesinato del secretario de la CGT José Ignacio Rucci en 1973, cuando Perón estaba en el poder. Tampoco relata a sus espectadores, muchos de los cuales no habían nacido en 1979 o no acceden a la historiografía, que el objetivo del contra-ataque montonero del cual los padres del protagonista son parte, tenía como objetivo exterminar físicamente a los directivos del equipo económico de la dictadura, movilizando manifestaciones obreras como si fuesen fuerzas de infantería que respaldan las acciones de las unidades combatientes clandestinas (Gillespie, 1982). El film adopta una visión acrítica del militarismo montonero, postura justificada por la desinformación en que vive el chico. 
La imagen habitual de los chicos en el cine expresa la idea que tiene el mundo de los adultos acerca de la infancia, caracterizada por la inocencia política y la falta de poder sobre sus propias vidas que despierte ternura y compasión. Mientras que el paso de la infancia a la adolescencia está signado en la vida real por el control social y las expresiones de resistencia, los protagonistas de las películas suelen encontrase alejados física y / o afectivamente de sus progenitores; son construidos como victimas inermes ante problemas que no comprenden. En lugar de los conflictos familiares entre padres e hijos, las películas suelen confrontar a los niños y adolescentes con los mecanismos de control, el discurso y la ideología, atribuyéndoles una perspectiva inocente que los libera del compromiso con el complejo mundo social. Las narrativas agravan los conflictos que en la realidad podrían ser no más que una anécdota, porque sin un conflicto agudo que el protagonista debe enfrentar, el film no cumple con el pacto de placer y catarsis implícito en las relaciones entre el cine de consumo masivo y sus espectadores (McNamee, 2000; Wilson, 2005; Tuñón y Tal, 2007). El conflicto del protagonista de Infancia clandestina con sus padres no estalla cuando le imponen una identidad ficticia o un modo de vida clandestino poco adecuado a la infancia, sino cuando le prohíben volver a la escuela y contactar con la chica de quien se ha enamorado, pero el desarrollo de la trama y el modo de representar los momentos de violencia traumática de la misma indican que el foco es la confrontación con la memoria del terrorismo estatal. Las tribulaciones de la pre-adolescencia y las consecuencias del militarismo montonero no son puestas en juicio.

La identidad ficticia funciona como metáfora, cambiándole el nombre Juan, que recordaba a Perón y sinónimo de pueblo, por Ernesto, en pos de Che Guevara, símbolo de apostolado revolucionario. El film construye una identidad basada en símbolos concordante con el modo de construcción del pasado por el discurso kirchnerista, hegemónico cuando Infancia Clandestina es producida y exhibida. El discurso kirchnerista construye lo político apelando a una mezcla de religiosidad y argumentación con un fuerte sesgo emocional y estético que adopta la memoria de la militancia peronista de los setenta para construir un ethos discursivo militante, informal, juvenil, transgresor y beligerante, que polariza la vida política entre sus adversarios potenciales o efectivos y el bando popular, hegemonizado por él mismo. La base de sustento político del discurso kirchnerista es heterogénea, pero no logra generar la confianza de las clases medias, de modo que relega la iconografía peronista en su apelación política, y no postula la veterana dicotomía peronismo-antiperonismo, que las alejaría. La identificación de Juan con Ernesto Che Guevara es también parte de la construcción selectiva de la memoria del Che, que idealiza su persona pero olvida el fracaso del proyecto del Foco Revolucionario que promovía. (Stephens, 2006; Rivera Pérez and Santillana, 2007; Tal, 2015)

La construcción en el film del pasado montonero sin explicitar su ideología, coincide con la tendencia del Nuevo Cine Argentino surgido a mediados de los noventa, donde las películas evitan enunciar posiciones políticas y definir "lo argentino", dejando la interpretación en manos de los espectadores. Las películas describen un mundo que presenta interrogantes en lugar de responder a interrogantes preexistentes; exhiben ambigüedades temáticas sin moralejas didácticas ni personajes que denuncian los mecanismos morales, psicológicos o éticos de la trama; evitan ser intencionalmente alegóricas y expresan desconfianza en las certezas políticas e ideológicas. El proceso de la producción permite la interacción entre hechos reales, el guión y el rodaje, haciendo de la película una herramienta de investigación y búsqueda personal de los cineastas. (Aguilar, 2006; Rangil, 2008) El cine es un aparato ideológico que porta en sí mismo la paradoja que relaciona mostrar con mirar. Las películas hechas por adultos muestran lo que se atribuye a la mirada infantil, pero la presencia del personaje infantil puede tener un efecto de crítica al aparato, rescatando el placer o el miedo imbuidos en el acto de mirar (Lury, 2005). Este efecto puede apreciarse en Infancia clandestina cuando el protagonista espía la 
reunión de los combatientes clandestinos (minuto 16 a 19), permitiendo al espectador tomar nota del militarismo montonero en el ritual de formación y entrega de armas, pero no accede a los planes. La película dirigida por Ávila reconstruye estéticamente la militancia de los padres, el compromiso y la disposición al sacrificio analógico al apostolado revolucionario de Che Guevara mencionado al principio, pero también recurre a la iconografía del Holocausto en las tomas del escondite en la pared doble donde Juan y su hermanito se ocultan al irrumpir los parapoliciales. La escena en que la abuela intenta sin éxito disuadir a su hija y yerno de la operación militar, o sacar a los chicos del entorno clandestino, llama la atención al precio que pagaron los hijos de los combatientes, que pierden no solo a los padres sino también la infancia. De este modo, el director se instituye como sujeto de una narración propia y heroica, descartando la representación más o menos idealizada como en películas documentales donde participan sobrevivientes de la generación de los padres, pero al mismo tiempo se alinea con la hegemonía ideológica contemporánea kirchnerista, en cuyo centro se ubican miembros de aquella generación setentista. (Amado, 2009; Aón, 2011; Bietti, 2008)

Imaginar y dibujar

Infancia clandestina representa mediante fragmentos de animación los momentos traumáticos de la historia de Juan que se refieren a la acción antidictatorial clandestina: el ataque parapolicial, el exilio, la estadía en Brasil separado de sus padres, la imposición de la identidad ficticia, el combate y suicidio del tío, las imágenes que pasan frente a sus ojos durante la operación represiva que irrumpe en la casa y el interrogatorio en el centro de detención ilegal. Dado que el discurso se refiere al terrorismo estatal de la dictadura a través del prisma del Genocidio, es posible inferir sobre dichos fragmentos de los usos de animación en representaciones del Holocausto. El film corto de animación Silencio (Orly Yadin y Sylvie Bringas, Israel, 1998) expone la experiencia de una sobreviviente del Holocausto desde un punto de vista infantil, combinando la animación con una parte menor de material filmado de archivo. En este film, la animación individualiza a la victima, recuperando su humanidad en un contexto donde se privaba de la misma al perseguido, al deportado y al muselman, situación análoga a la del desaparecido a manos de la dictadura. La animación de-construye la ilusión realista, es un artificio que supera la oposición en el discurso del Holocausto a representar estéticamente lo irrepresentable, postura hegemónica cuando la película fue producida. La animación también explicita la fluctuante naturaleza de la posición del sujeto y de-construye las meta-narrativas en el caso de Vals con Bashir (Folman, Israel, 2008), largometraje animado con pocos minutos de material de archivo, que relata la participación del director como soldado conscripto en la primer guerra del Líbano en 1982 y su inconsciente función en torno a la masacre de Sabra y Shatila. (Copley, 2010; Peaslee, 2011)

La animación constituye la mayor parte del texto cinematográfico en los ejemplos mencionados, mientras que en Infancia clandestina solo algunas breves escenas son animadas. El uso de la animación en los filmes antes mencionados adquiere un sentido contra-hegemónico respecto a narrativas consagradas y modo de representación convencional, en cambio, la animación de escenas traumáticas en Infancia clandestina es convencional y melodramática. La paleta de colores cenicientos infunde espanto y tristeza, los planos son casi monocromáticos. El montaje crea confusión, acompañado por una banda de sonido impactante y estremecedora. Todo esto orienta las emociones del espectador sin representar una alternativa a narrativas o discursos hegemónicos, que desde los primeros filmes documentales de hijos, como Los rubios, les hace eco aceptando el particular enfoque de quienes fueron privados de una infancia convencional.

\section{Conclusión}


Las narrativas cinematográficas de infancia bajo la dictadura en películas destinadas al público general pueden ser interpretadas como alegorías de las retóricas de la memoria, donde la representación del pasado construye imágenes que testimonian la tensión entre el recuerdo y el olvido, condicionada por los conflictos entre discursos del presente. Memoria clandestina prosigue una corriente de cine de Hijos de desaparecidos, ofreciendo una visión que idealiza a los combatientes Montoneros del pasado pero también cuestiona el precio personal que pagan los huérfanos de los desaparecidos. Esta variante, alternativa a la memoria de la generación setentista constituida en el discurso kirchnerista y difundida en el cine, no se contrapone a dicha hegemonía ideológica sino se deslinda como un memoria particular que se ve parte de dicho discurso.

\section{Bibliografía}

Aguilar, G. (2006). Otros mundos - Ensayo sobre el nuevo cine argentino. Buenos Aires: Santiago Arcos Editor.

Amado, A. (2009). La Imagen justa. Cine argentino y política (1980-2007). Buenos Aires: Colihue.

Aón, L. (2011). Una cuestión de representación: las películas de los directores-hijos. Estudios número 25, 219230. (2009). El cine de los hijos de desaparecidos: Los Rubios y M. Ponencia presentada en

Primer Encuentro sobre Juventud, Comunicación e Industrias Culturales, Bs. As. Disponible en:

http://www.perio.unlp.edu.ar/observatoriodejovenes/sites/perio. unlp.edu.ar.observatoriodejovenes/files/aon.pdf .

Baer, A. (2006). Holocausto. Recuerdo y representación. Madrid: Losada.

Berger, V. (2008). La búsqueda del pasado desde la ausencia: Argentina y la reconstrucción de la memoria de los desaparecidos en el cine de los hijos, Quaderns de Cine: Cine i memòria històrica, número 3, 23-36.

Bietti, L. (2009). Entre la cognición política y la cognición social: el discurso de la memoria colectiva en Argentina. Discurso \& Sociedad, número 1, 44-89.

(2008). Memoria, violencia y causalidad en la Teoría de los dos Demonios. El Norte - Finnish Journal of Latin American Studies, número 3, 1-34.

Copley, J. (2010). Modes of representing the Holocaust: A discussion of the use of Animation in Maus and Silence. Opticon1826, número 9. Disponible: http://dx.doi.org/10.5334/ opt.091003

Dufays, S. (2014). El niño en el cine argentino de la postdictadura (1983-2008). Alegoría y nostalgia. Sufolk and Rochester: Boydell \& Brewer.

Feinmann, J. P. (2012). El año que vivimos en peligro. Radar --Página 12 16/12. Disponible: http://www.pagina12.com.ar/diario/suplementos/radar/9-8231-2012-09-19.html

Feierstein, D. (2011). El genocidio como práctica social: entre el nazismo y la experiencia argentina, Buenos Aires, Fondo de Cultura Económica.

Ferro, M. (1988). Cinema and History. Detroit: Wayne University Press. 
Gillespie, R. (1982). Soldiers of Perón - Argentina's Montoneros. New York: Oxford University Press.

Hardt, H., Rivera Perez, L. and Calles Santillana, J. (1998). The Death and Resurrection of Ernesto Che Guevara - US Media and the Deconstruction of a Revolutionary Life. International Journal of Cultural Studies número 1, 351-372.

Huyssen, A. (2000). En busca del tiempo futuro, Revista Puentes, número 2. Disponible:

https://docs.google.com/viewer?url=http\%3A\%2F\%2Fi3xp6.w.incapsula.net\%2F

modulo\%2Fupload\%2FHuyssen.pdf

Korstanje , M. (2014). Daniel Feierstein: El genocidio como práctica social: entre el nazismo y la experiencia argentina. OBETS Revista de Ciencias Sociales, número 1, 227-233.

. (2011). El culto K en la era contemporánea: Crónica, génesis y apoteosis del proceso Kirchnerista. Contribuciones a las Ciencias Sociales. Disponible: www.eumed. net/rev/cccss/13/

LaCapra, D. (2005). Escribir la Historia, escribir el Trauma. Buenos Aires: Nueva Visión.

Lury, K. (2007). The Child in film and television: Introduction. Screen número 3, 307-314.

Marzorati, Z. y Tal, T. (2011). Introducción al Dossier: Memorias, Identidades y Cine - Perspectivas contemporáneas sobre la imaginación del pasado. Imagofagia - Revista virtual de la Asociación Argentina para el estudio del cine y el audiovisual. Disponible: http://www.

asaeca.org/imagofagia/index.php/imagofagia/article/view/157

McNamee, S. (2000). Foucault's Heterotopia and Children Everyday Lives. Childhood: A Global Journal of Child Research, número 4, 479-492.

Martin, D. (2011). Wholly ambivalent demon-girl: horror, the uncanny and the representation of feminine adolescence in Lucrecia Martel's La niña santa. Journal of Iberian and Latin American Studies, número 17, 5976.

Montealegre Iturra, J. (2012). El imaginario del Holocausto en la memoria social de las dictaduras latinoamericanas. Cultura, lenguaje y representación, número 10, 97-110.

Montero, A. (2009). Puesta en escena, destinación y contradestinación en el discurso kirchnerista (Argentina, 2003-2007). Discurso \& Sociedad, número 2, 316-347.

Murillo Saban, X. (2013). Infancia Clandestina (2011): del pasado histórico al presente político. Ponencia presentada en II Congreso Internacional Historia, literatura y arte en el cine en español y portugués: De los orígenes a la revolución tecnológica del siglo XXI, Salamanca, 26-28 de junio de 2013. Disponible: http://www.cebusal.es/download/publicaciones/ Actas_online_II_Congreso_Cine_Salamanca\%20sin\%20hiperv\%C3\%ADnculos.pdf 
Peaslee, R. (2011). It's Fine as Long as You Draw, But Don't Film: Waltz with Bashir and the Postmodern Function of Animated Documentary. Visual Communication Quarterly, número 4, 223-235.

Rangil, V. (2008). Introducción. Cine argentino de hoy, ed. Rangil, V. Buenos Aires: Biblos, 11-22.

Rosenstone, R. (1995). Visions of the past: the challenge of film to our idea of history. Cambridge: Harvard University Press. Sorlin, P. (1980). The Film in History: Restaging the Past. Oxford: Black and Blackwell.

Stephens, G. (2006). Che's America in Myth, Memory and Contemporary Reality. EIAL número 1, 185-195.

Tal, T. (2015). “Etnicidad, memoria y alegoría histórica en narrativas de pubertad judía”, Toma Uno 4, Departamento de Cine y Televisión, Universidad Nacional de Córdoba, Argentina, p. 219-226. . (2012). Jewish Puberty in Contemporary Latin American Cinema: Constructing Judeo-Latinidad. Returning to Babel: Jewish Latin American Experiences, Representations and Identity. Ed. Ran, A. and Cahan, J. Leyden: Brill Press, 143.156.

(2009). La Rosales: Historia, intertextualidad y alegoría en una película de la transición a la Democracia en Argentina. Història \& Cinema. Ed. Caparrós Lera, J. (2009). Barcelona: Publicacions i Edicions Universitat de Barcelona, 243-262.

. (2005). Alegorías de memoria y olvido en películas de iniciación: Machuca y Kamchatka. Aisthesis número 38, 136-151. (2001). Inclusión política y exclusión genérica: metáforas familiares en películas de Cine Liberación. Taller - Revista de Sociedad, Cultura y Política, número 17, 148-160.

Tandezciarz, S. (2012). Secrets, Trauma, and the Memory Market (or the return of the repressed in recent Argentine post-dictatorship cultural production). Cinema Journal, número 2, 62-71.

Traverso, A. and Broderick, M. (2010). Interrogating trauma: Towards a critical trauma studies. Continuum: Journal of Media \& Cultural Studies, número 1, 3-15.

Tuñon, J. y Tal, T. (2007). La infancia en las pantallas fílmicas latinoamericanas: entre la idealización y el desencanto. En: Historia de la Infancia en América Latina, eds. Rodríguez, P. y Manarelli, M. Bogotá: Universidad Externado de Colombia, 649-668.

Varela, M. (2016). Épica, ficción y documental. Revista Ñ, 4/3/2016. Disponible http://www. revistaenie.clarin.com/ideas/Epica-ficcion-documental_0_1534646529.html

Wilson, E. (2005). Children, emotion and viewing in contemporary European film. Screen número 3, 329-340.

Xavier, I. (1998). Allegory and History. En: Stam, R. and Miller, T. (eds.). A Companion to Film Theory. Oxford: Blackwell Publishers, 333-362.

Filmografía 
El año que mis padres salieron de vacaciones (Hamburguer, C., Brasil, 2006).

La Historia Oficial (Puenzó, L., Argentina, 1984).

Infancia Clandestina (Ávila, B., Argentina,. 2001).

Kamchatka (Piñeyro, M., Argentina, 2002).

Machuca (Wood, A., Chile, 2004).

Silencio (Yadin, O. y Bringas, S. Israel, 1998).

Vals con Bashir (Folman, A., Israel, 2008).

Abstract: Analyzing the allegorical and ideological functions of cinematographic initiation narratives centered on children's characters reminiscent of military dictatorships, the presence of the concept of genocide in the discourse on state terror exercised by the last military civic dictatorship and the uses of animation as an aesthetic artifact which represents traumatic moments considered unrepresentable through realistic aesthetics, the article argues that clandestine childhood continues a particular stream of movies of children of disappeared, offering a vision of the past that idealizes the Montoneros fighters but questions the personal price paid by orphans. This variant, an alternative to the cinematographic memory of the generation linked to the experience of the Montoneros guerrilla, is not opposed to the hegemonic discourse during the governments of Nestor Kirchner and Cristina Fernández de Kirchner, but rather as a particular memory that is part of the Kirchners speech.

Key words: allegory - childhood - discourse - Holocaust - genocide - memory

Resumo: Analisando as funções alegóricas e ideológicas de narrativas cinematográficas de iniciação centradas em personagens infantis que lembram as ditaduras militares, a presencia do conceito de genocídio no discurso sobre o terror estatal exercido pela última ditadura cívico militar e os usos da animação como artefato estético que representa momentos traumáticos considerados irrepresentáveis mediante a estética realista, o artigo sustém que Infância clandestina prossegue uma corrente particular de cinema de filhos de desaparecidos, oferecendo uma visão do passado que idealiza aos combatentes Montoneros mas questiona o preço pessoal que pagam os órfãos. Esta variante, alternativa à memória cinematográfica da geração vinculada à experiência da guerrilha montonera, não se contrapõe ao discurso hegemônico durante os governos de Néstor Kirchner e Cristina Fernández de Kirchner, senão se deslinda como uma memória particular que se vê parte do discurso kirchnerista.

Palavras chave: alegoria - infância - discurso - holocausto - genocídio - memória.

La estética del trauma y el discurso de la memoria: personajes infantiles ante el terror estatal en Infancia clandestina (Ávila, Argentina, 2011) fue publicado de la página 63 a página73 en Cuadernos del Centro de Estudios de Diseño y Comunicación $\mathrm{N}^{\circ} 68$ 